\title{
The use of essential oils as a complementary treatment for anxiety
}

\author{
Fradelos E. ${ }^{1}$, Komini A. ${ }^{2}$ \\ ${ }^{1}$ State Mental Hospital of Attica "Daphne”, Greece \\ ${ }^{2}$ Athens, Greece
}

\begin{abstract}
Email address:
evagelosfradelos@hotmail.com (E. Fradelos),minakom2003@hotmail.com (A. Komini)
\end{abstract}

\section{To cite this article:}

Fradelos E., Komini A.. The Use of Essential Oils as a Complementary Treatment for Anxiety. American Journal of Nursing Science. Special Issue: Mental Health Care: Aspects, Challenges and Perspectives. Vol. 4, No. 2-1, 2015, pp. 1-5. doi: 10.11648/j.ajns.s.2015040201.11

\begin{abstract}
Mental disorders occur in people in all countries, societies and in all ethnic groups, regardless socio-economic order with more frequent anxiety disorders. Through the process of time many treatment have been applied in order to address this complex mental issue. People with anxiety disorders can benefit from a variety of treatments and services. Following an accurate diagnosis, possible treatments include psychological treatments and mediation. Complementary and alternative medicine (CAM) plays a significant role in health care systems. Patients with chronic pain conditions, including arthritis, chronic neck and backache, headache, digestive problems and mental health conditions (including insomnia, depression, and anxiety) were high users of CAM therapies. Aromatherapy is a holistic method of treatment, using essential oils. There are several essential oils that can help in reducing anxiety disorders and as a result the embodied events that they may cause.
\end{abstract}

Keywords: Essential Oils, Anxiety, Treatment

\section{Introduction}

Mental disorders occur in people in all countries, societies and in all ethnic groups regardless socio-economic order. The prevalence is estimated to be $10 \%$ for adults, and it is estimated that about $20 \%-25 \%$ percent of the population will suffer by a mental disorders at least once in their lifetime [1]. In Greece, mental disorders are frequent. Epidemiological studies that have been carried out in the general population show that $14 \%-16 \%$ of Greeks suffer from a psychiatric disorder, with more frequent anxiety disorders. In a study that was conducted by the World Health Organization, in which Greece participated, it was found that $22 \%$ of those visiting primary health care are suffering from a psychiatric disorder during the last month and the importance of prevention of them is given by the psychiatric community $[2,3]$. There are many explanations of the etymology of the word anxiety some of them claim that the word anxiety derives from IndoGermanic root Angh, which means to constrict, to narrow, or to strangulate others from the Greek word anchein which means to strangle, to suffocate, or to press shut [4]. All this indicates that anxiety isn't a problem of our time. In a matter of fact there are several literary reports and antiquity myths demonstrate that symptoms of what we name anxiety disorders nowadays were observed long ago. Maybe one of the oldest examples lies in Greek mythology - the god Pan. He was responsible for anxiety and was the origin of the term "panic"[5]. Through the process of time many treatments have been applied in an effort to address this complex health problem. Aromatherapy and essentials' oils have been applied too and have been demonstrating remarkable results in the treatment of anxiety.

The aim of the present study is to present the use of essential oils and aromatherapy as a complementary treatment for anxiety. Moreover this study aims to present in which cases and how essential oils can be effective in order to address this complex issue of anxiety.

\section{Materials and Methods}

The material of study consists of articles and publications concerning the effect that aromatherapy and essential oils can have in the reduction of anxiety. Literature reviews as well as research articles that were found mainly in the Medline electronic database, the Hellenic Academic Libraries Link (HEAL-Link) and in the Google Scholar search engine were used. The literature review was conducted between April and August of 2014. The search was conducted using the key words: essential oils, anxiety and treatment. 


\section{Anxiety Disorders}

The term "anxiety disorders" includes disorders that share features of excessive fear and anxiety and related behavioral disturbances. Fear is the emotional response to real or perceived imminent threat, whereas anxiety is anticipation of future threat. Obviously, these two states overlap, but they also differ, with fear more often associated with surges of autonomic arousal necessary for fight or flight, thoughts of immediate danger, and escape behaviors, and anxiety more often associated with muscle tension and vigilance in preparation for future danger and cautious or avoidant behaviors [6]. Generally speaking, anxiety disorders are the most common mental disorders globally and it seems that women tend to be more affected by them than men are [7]. The term of anxiety disorders encloses various categories included in it, such as panic attacks, generalized anxiety disorder, social phobia [6-8]. The anxiety disorders differ from one another in the types of objects or situations that induce fear, anxiety, or avoidance behavior, and the associated cognitive ideation. Thus, while the anxiety disorders tend to be highly comorbid with each other, they can be differentiated by close examination of the types of situations that are feared or avoided and the content of the associated thoughts or beliefs [6].

Regardless the classification and the various subtypes we should consider anxiety as a continuous line, which is inversely proportional to the perception, meaning the highest levels that one has the less awareness on the surrounding. Anxiety is a multidimensional phenomenon that affects one's life in various ways. The effects that anxiety has can affect the body, cognitive functioning, behavior as well as the emotional and social state of the person that is experiencing that [9].

Paradoxically, anxiety is a complex and useful mental function. It generates a range of behaviors that occur in response to any threat. During the last years, research into the phenomenology, pathophysiology, and neurobiology of anxiety disorders has grown so much, that results translatable into clinical practice may offer hope and help to people with anxiety disorders [5].

Through the process of time, several treatments have been applied in order to address this complex mental issue. The therapy selection has been under the same reformation as the perception of health and human body in general. People with anxiety disorders can benefit from a variety of treatments and services. Following an accurate diagnosis, possible treatments include psychological treatments and mediation $[10,11]$.

Complementary and alternative medicine (CAM) plays a significant role in health care systems. CAM therapies have increasingly attracted the attention of medical doctors and researchers as well as the public, the government and the media. Patients with chronic pain conditions, including arthritis, chronic neck and backache, headache, digestive problems and mental health conditions (including insomnia, depression, and anxiety) were high users of CAM therapies.
These disorders are not easily treated with conventional medical therapies. Of the reported cases of anxiety, more than $40 \%$ patients use CAM [11-14]. In an effort to address the anxiety disorders and the promotion of mental health various alternative and complementary methods are recruited. Nowadays we can come across to pets, yoga and meditation in the effort to reduce the anxiety levels that one's experiencing [10]. Among these treatments we can find aromatherapy and essential oils and their application to reduce anxiety.

\section{Aromatherapy}

Aromatherapy is an holistic method of treatment, using essential oils. Essential oils are volatile and liquid aroma compounds form natural sources, usually plants[15]. There is not a standardized definition for what aromatherapy is. The term "aromatherapy" first coined by Rene-Maurice Gateffosse in 1928, who was the first to explore the chemical composition of essential oils in relation to their therapeutic properties. It is a complementary/ alternative form of treatment that uses essential oils in order to improve physical and mental wellbeing, balance and mood. Essentials oils we can say that include the vital force and energy of a plant or herb, thus can say that are a pure and natural form of energy [16]. Due to the abilities that essential oils have they can also be used for beautifying and therapeutic purposes [15]. Aromatherapy can be applied in a combination with various traditional and complementary treatments [16].

Aromatherapy is wholly dependent on the notion of chemotypes. This is used to define the biochemically-active molecule(s) on any number of clinical pathologies. The combination of this notion with that of the rigor of Latin denominations, results in a near-perfect knowledge of the mode of action of essential oils [3-17]. Chemotype indicates visually identical plants but having different, chemical components, resulting in different therapeutic properties [18]. Nervousness, tension and stress, call for the sedative qualities of aldehydes, the diverse action of ester components on the central nervous system, and the sympatholytic effects (calming, dilation of blood vessels, lowering blood pressure) of some phenylporpanes [19].

No one can say for sure whether extraction and use of aromatic material began in India or Egypt. In India the use of plants and plant extracts as medicines has been continuous from at least 5000 years ago up to the present day. On the other hand Egyptians used plants in the same era for many purposes, from hygienic use to embalming. Greeks, about four or five hundred years before Christ, made a vital contribution to the future study of plant medicine by classifying and indexing the knowledge they had gained from the Egyptians [20]. Despite the antiquity of essential oils usage, aromatherapy started to achieve a certain level of acceptance by conventional doctors in France and insurance companies even paid for treatments, after Paul Belaiche published in 1978 his study on clinical uses of aromatherapy for treating a wide range of infectious and degenerative illnesses [19]. 
Essential oils may be found in different parts of the plant. Common techniques used for the extraction of essential oils are: hydrodistillation, hydrodiffusion, effleurage, cold pressing, steam distillation, solvent extraction, microwave assisted process, carbondioxide extraction. The adopted techniques depend on the part of the plants where the oil is to be extracted, the stability of the oil to heat and susceptibility of the oil constituents to chemical reactions [15].

The essential oils have internal or external use. There are few ways in which essential oils are administrated for use in aromatherapy. Its way has a specific root by which the essential oil comes through in the body, differs depending the reason we using it and has different outcomes [21].

Those ways are: Inhalation: The essential oil enters the body through breathing. A method recommended for improving mood and mental wellness and for problem of the respiratory system. Pads: Pads (compresses) with essential oils can soothe pain, sprain or swelling and reduce inflammation. Mouthwashes: Gargling mixtures by essential oil seems to have the ability to relieve the irritated mucosa of the mouth. Baths with essential oils provide relaxation, stress reduction and hydration level of the skin. Hippocrates, the father of medicine, wrote that the best way to be healthy is one to enjoy a daily massage with scented bath. Its worth to be mention that baths and hydrotherapy are applied upon mental illness from antiquity until about the first half of the $20^{\text {th }}$ century $[21,22]$. Perfuming the area: The evaporation of essential oils is applied to clean the space of germs, disinfection and antisepsis, Moreover in that way a pleasant fragrance is filling the place and eliminates the unpleasant odors in addition to the improvement of the mood. Massage: The essence of aromatherapy lies upon the transfer of essential oils into the body through the skin. Some essential oils are not allowed to come into direct contact with the skin in their original form, due to toxicity. We therefore need a substance that will be mixed with the essential oil and will penetrate inside the body through massage. [21].

In order to describe better the use of essential oils, we categorize it in two groups: in these that affect physically the human body and these that affect human's psychology. The first group is further categorized in essential oils that: 1) affect human body through nervous system 2) affect directly an organ or tissue. The second group is more difficult to be defined before the use, as it depends on each human body's reaction [23].

\section{Aromatherapies Applications in Anxiety}

In holistic health all parts of the person, cells, organs, body systems and emotions affect each other as well as the whole person [23]. No part or system can be diseased or damaged without affecting, or causing disease or damage to, the remaining whole. For example, stress tension can cause protein to be released from cells. These proteins, elements of the immune system, cause allergic reaction that result in symptoms of atopic dermatitis. A connection also exists between dermatitis and a deficiency of essential dietary fats. This fat deficiency is also thought to produce anxiety. The body is quite complex, so holistic analysis rarely is a simple task. Essential oils have holistic, multi-therapeutic functions: they work by correcting or regulating many imbalances simultaneously [16].

Essential oils can affect a person psychology and regulate emotions. The molecules of essential oils when inhaled, directed to the sensory cells of the olfactory scheme. Since each sensor cell flowing minutes setae, which record information on perfumes, and transferring it into the center of the brain through the olfactory valve. These cause the release of neurochemical substances, which may be soothing, relaxing, and excitatory or cause euphoria. Furthermore, aromatic particles enter the nervous system resulting in the relaxation, tranquility, and relieve nerves and hence of nerve centers in the brain. Due this anxiety, affective disorders, headaches, migraines can be addressed in some way [19].

According to literature and research articles, there are several essential oils that can help in reducing anxiety disorders and as a result the embodied events that they may cause. Reported data claim that Piper Methysticum and Bacopa Monniera are associated with anxiolytic activity in humans. In another trial on generalized anxiety disorder in hospital based clinical set up, Ocimumn sanctum significantly attenuated generalized anxiety disorders and also attenuated its correlated stress and depression [11].

As we move on to the literature review more and more research indicating the positive effects that aromatherapy can have in the reduction of anxiety. Results from a pilot study conducted by Jennifer Edge an occupational Therapist back in 2003 where essential oils applied by a massage session was shown to have a positive effect on both levels of anxiety and relaxation over a short term period. Each client was seen for six aromatherapy massage sessions of $1 \mathrm{hr}$ duration and an initial consultation session. The massage was performed at the same time of day and day of the week for each client in a specific room was allocated for aromatherapy use. Each client received the same standardized massage technique from the same therapist although the essential oils were selected and blended specifically for each session/ individual client [24].

In a recent research contacted by Cho and associates, between August 1, 2010, and November 20, 2010, at the Eulji University Hospital in Daejeon, Korea, aromatherapy essential oils were blended with lavender, roman chamomile, and neroli with a $6: 2: 0.5$ ratio. Lavender suppresses heart stimulation and lowers blood pressure; therefore, it is useful in the treatment of heart acceleration and high blood pressure. Chamomile has a calming effect and is effective in relieving anxiety and stress, and neroli has a calming effect and is effective in treating insomnia. Participants received 10 times treatment before PCI, and the same essential oils were inhaled another 10 times after PCI. The results, in summary, were that aromatherapy reduced anxiety, increased sleep, and stabilized the BP of patients undergoing cardiac stent 
insertion. Furthermore the anxiety level of the aromatherapy group was significantly lower than that of the control group[ 26 ].

According to Dominique Baudoux, essential oils that can be used to reduce anxiety ans stress are: Citrus Bergamia, Citrus Aurantium, Chamaemulum nobile, Pelargonium asperum, Laurus nobilis, Lavandula burnatii, Lavandula angustifolia, Citrus reticulata, citrus sinensis, Ravensara aromatic and Canaga Odorata [17]. Moreover according to Schnaubelt K. a great aroma therapist, among others, anxiety can be reduced by using neroli, levandula, citrus reticulate, rosemarinus officinalis and lemon verbena essential oils[18]. In addition other essential oils referred by Battaglia S., to front stress are basil, bergamot, roman chamomile, german chamomile, virgian cedarwood, atlas cedarwood, clary sage, frankincense, geranium, jasmine absolute, lavender, lemon, sweet marjoram, may chang, neroli, Melissa, sweet orange, petitgrain, rose otto, rose absolute, rosemary, rosewood, sandalwood, tangerine, vetiver, ylang ylang [21]. Shirley Price, one of the most well know aroma therapist, in one of her books anxiety may be reduced be using the following essential oils: basil, bergamot, cedrawood, chamomile, roman, clary, geranium, levander, lemon, marjoram, Melissa, myrrh, neroli, sweet orange, patchouli, petitgrain, rose otto, rosewood, thyme, valerian, vetiver and ylang ylang[4]. In another book of the same writer, the following essential oils are referred as balancing, calming, and uplifting: chamaemelum nobile, citurs aurantium, citrus bergamia, lavandula angustifolia, lavandula intermedia, origanum marjorana, pelargonium graveolens [27].

In fact levanter essential oil has been applied in various populations. Results from a study showed that aromatherapy inhalation (a mixture of Lavender and Rose essences) has a noticeable effect on the decreasing of symptoms of anxiety among female students who are living in the dorm. The aromatherapy led to reduction of students' anxiety after applying it in the second and fourth week [28].

Despite the fact that sometimes complementary treatments such us aromatherapy are addressed with criticism didn't stop researchers to applied them in various group of patients. For example anxiety symptoms could be found in cancer patients as a psychological effect of their severe illness in many cases in which a complementary treatment could be used to address those symptoms. According to a study in 2007 a four weekly sessions of aromatherapy massage improves clinical anxiety and/or depression experienced by cancer patients up to 2 weeks after the end of the intervention. Although improvement in self-reported anxiety was evident up to 6 weeks post intervention, no evidence of benefit for aromatherapy massage on pain, insomnia, nausea and vomiting, or global quality of life at either assessment point were found [29].

As we see, according to bibliography and scientific essays, essential oils can be used individually or combined according to their chemo type, in aromatherapy massage treatments or in sessions of inhalation, in order to reduce stress and anxiety as an effective complementary therapy.

\section{Conclusions}

Aromatherapy is not a new age therapeutic technique, its origin can be traced back in ancient time and as all complementary treatments its use has been increased over the years. There are different ways and many in number essential oils that can be applied depending on the condition. Literature review and most of the researches have shown that aromatotherapy causes various actions favorable for patients such as relaxation, reductions in anxiety, depression and fatigue, and improvements in quality of life via nervous, endocrine, immune, and circulatory systems, there for could be applied as a complementary therapy for people with anxiety symptoms. However, as all the complementary treatments, it should not overlap the doctor's instructions, especially in severe cases. Finally it should be noted that aromatherapy must be applied only according to the instructions of qualified aromatherpists and that strictly the essential oils that are used should not be adulterated

\section{References}

[1] The World Health Report 2001: Mental Health: New Understanding, New Hope. World Health Organization, Geneva, 2010.

[2] Statharou A, Papathanasiou I, Gouva M, Masdrakis B, Berk A, Ntaragiannis A, Kotrotsiou E. Investigation of burden in caregivers of the mentally ill. Interscientific Health Care 2011; 3(2): 59-69.

[3] Lionis Ch. Prevalence of mental disorders in primary health care and the role of the general and family doctor: Experiences from Greece. Psychiatry 2003; 1: 20-23.

[4] Westerberg H, Den Bor A, Murphy D. Advances in the neurobiology of anxiety disorders. John wiley \& sons. West Sussex. 1996, pp 3-4.

[5] Nardi A, Fontenelle L, Crippa JA. New trends in anxiety disorders. Revista Brasileira de Psiquiatria 2012; 34(Suppl. 1): 5-6.

[6] Diagnostic and Statistical Manual of Mental Disorders, Fifth Edition. Arlington, VA, American Psychiatric Association 2013, pp189-190.

[7] Sadock B, Sadock V. Kaplan and Sadock's pocket handbook of clinical psychiatry, Third edition. Parisianos Publishing. Athens 2004, pp191-210.

[8] World Health Organisation. ICD-10 Classifications of Mental and Behavioural Disorder: Clinical Descriptions and Diagnostic Guidelines. Geneva 1992.

[9] Kneisl C, Wilson H, Trigoboff E. Contemporary PsychiatricMental Health Nursing. Hellin Publishing, Athens 2009, pp124-147.

[10] Fradelos E. Animal assisted therapy for psychiatric patients: A systematic review. Scientific Chronicles 2014;19(2): 132-143.

[11] Shri R. Anxiety: Causes and Management. International Journal of Behavioral Science 2010; 5(1);100-108. 
[12] Kessler C, Soukup J, Davis B, Foster F, Wilkey A, Van Rompay I, Eisenberg M. The use of complementary and alternative therapies to treat anxiety and depression in the United States. American Journal of Psychiatry 2001; 158(2):289-294.

[13] Elkins G, Rajab H, Marcus J. Complementary and alternative medicine use by psychiatric inpatients. Psychological Reports 2005; 96(1):163-166.

[14] Papathanasiou I, Kotrotsiou E. Alternativee methods for healing pain. Hellenic Journal of Nursing 2000, 39(2): 131138.

[15] Hamid A., Aiyelaagb O, Usman A. Essential oils: Its medicinal and pharmacological uses. International journal of Current research 2011; 3(2):086-098.

[16] Harrisson J. Aromatherapy: Therapeutic use of essential oils for esthetics. Cengage Learing. Australia 2008, p.29

[17] Baudoux D. Aromatherapy: healing with essential oils, douce alternative. Publisher Amyris 2007.

[18] Price S. Aromatherapy for health professionals. Fourth edition. Churcill Livingstone 2012, p.4.

[19] Schnaubelt K. Advanced aromatherapy: The Science of Essential oil Therapy. Healing Arts Press, Rochester 1995, p.8.

[20] Price S. Aromatherapy Workbook. Thorsons an imprint of Harper Collins Publishers, London 1995, p.2,3.

[21] Battaglia S. The complete guide to aromatherapy. The international Centre of Holistic Aromatherapy, second edition, Australia 2003, p.86.
[22] Tsitsis N, Polkas G, Daoutis A, Prokopiou E, Kourkouta L. Hydrotherapy In Ancient Greece. Balkan Military Medical Review.2013; 16(4): 462 - 466.

[23] Katsiotis S, Chatzopoulou P. Aromatic Pharmaceutical Plants and Essential oils. Kiriakidi publishing, second edition. Athens 2013, p.559

[24] Papathanasiou I., Kourkouta L., Sklavou M. Holistic Nursing Care: Theories and Perspectives. American Journal of Nursing Science 2013; 2(1): 1-5.

[25] Edge J. A pilot study addressing the effect of aromatherapy massage on mood, anxiety and relaxation in adult mental health. Complementary Therapies in Nursing \& Midwifery 2003; 9:90-97.

[26] Cho M, Min E, Hur M, Lee M. Effects of Aromatherapy on the Anxiety, Vital Signs, and Sleep Quality of Percutaneous Coronary Intervention Patients in Intensive Care Units. Evid Based Complement Alternat Med 2013; 2013: 381381.

[27] Price S. Aromatherapy for health professionals. Fourth edition, Churcill Livingstone 2012.

[28] Mirkarimi S, Najafi L, Ghiasi M, Kamalvand A, Mahalleh H, Bahman M. Studying the Effect of Aromatherapy Inhalation on Female Students' Anxiety Living in Dormitory Complex of Tehran University of Medical Sciences. International journal of pharmaceutical science and health care 2011; 1(3):105-110.

[29] Wilkinson M, Love B, Westcombe M, Gambles A, Burgess C, Cargill A, Young T, Maher J, Ramirez J. Effectiveness of aromatherapy massage in the management of anxiety and depression in patients with cancer: A multicenter randomized controlled trial. Journal of Clinical Oncology2007; 25(5):532 539 . 